\title{
Cecília Meireles: “a Bela e a Fera” e “a Bela e as Feras”
}

\section{Cecília Meireles: "the Beauty and the Beast" and "the Beauty and the Beasts"}

\author{
Lilia Maria Machado Souza
}

\begin{abstract}
Resumo: Cecília Meireles, além de poetisa, muito escreveu em prosa, incluindo crônicas de viagem. Uma delas, "A Bela e as Feras”, é aqui objeto de análise, associada ao conto “A Bela e a Fera”, com o qual apresenta intertextualidade já a partir do título. A história da crônica no Brasil aponta uma grande adaptação do gênero em nosso país, enquanto esse conto infantil tem sido reaproveitado e reelaborado através dos tempos, prestando-se a subsidiar também tal crônica ceciliana. Aqui se pretende mostrar como a autora se utiliza do conto para, no texto de sua autoria, suscitar uma reflexão a respeito das dualidades existentes nos seres humanos. As imagens poéticas encontradas na crônica analisada, carregadas de contrastes e sentidos, e associadas ao imaginário mágico dos contos de fada, provocam o confronto entre aparência e essência nas criaturas, mostrando que a crônica de Cecília Meireles é atemporal, e a autora inesgotável.

Palavras-chave: Cecília Meireles. Crônica. Contos de fada. A Bela e a Fera. A Bela e as Feras.

Abstract: Cecília Meireles, besides being a poet, wrote in prose a lot, including travel chronicles. One of them, "The Beauty and the Beasts", is the object of analyses here, associated with the short story "The Beauty and the Beast", with which shows intertextuality since its title. The chronicle history in Brazil points a great genre adaptation in our country, while this children’s short story has been reused and redrawn throughout times, being used to subsidize such Cecília's chronicle as well. Here, it is intended to demonstrate how the author uses the short story to promote, in her own text, a reflection about the existing dualities in the human beings. The poetic images found in the analyzed chronicle, full of contrasts and meanings, and associated to the fairy tales magical imaginary, cause the confrontation between the creatures appearance and essence, showing that Cecília Meireles chronicle is timeless and the author inexhaustible.
\end{abstract}

Key words: Cecília Meireles. Chronicle. Fairy tales. The Beauty and the Beast. The Beauty and the Beasts.

*Especialista sem vinculação institucional. E-mail: liliasouza@uol.com.br. Curitiba - PR 
1 Introdução

Pastora de nuvens, com a face deserta,/ sigo atrás de formas com feitios falsos

Cecília Meireles

É de amplo conhecimento e alvo de grande estudo o trabalho poético de Cecília Meireles (1901-1964). Ela é aclamada como a maior poetisa de nosso país, quiçá da língua portuguesa. Indubitável se faz a grandeza do acervo por ela deixado nesse campo. Sua prosa, contudo, não deixa a desejar. Dotada de múltiplos interesses e aptidões, Cecília foi jornalista, professora, defensora da educação, folclorista, literata, estudiosa de várias culturas e idiomas e com interesse por assuntos vários. Além de seu trabalho em versos, Cecília Meireles - a "pastora de nuvens" - muito produziu em prosa: escreveu peças teatrais, livros didáticos, ensaios, conferências, artigos, contos, crônicas. Para se pensar na amplitude de seu trabalho nessa área, lembremos que a Nova Fronteira fez o planejamento editorial para publicar em não menos que 23 tomos a obra em prosa de Cecília. Tal projeto incluiu seis tomos apenas para as crônicas escritas pela autora, sendo três deles com crônicas de viagem. E é justamente a respeito de suas crônicas de viagem que aqui se fala.

Cecília muito viajou pelo Brasil e também por diversos países, onde realizava conferências. Suas crônicas (geralmente, à época, publicadas em jornais ou revistas) relatam experiências e reflexões de viagens realizadas entre 1934 e 1962. (AZEVEDO FILHO, 1998). São textos repletos de beleza, sensibilidade e delicadeza, características tão conhecidas nos poemas da autora. E ao leitor fica nítido que, na prosa de Cecília, a poeta ladeia a prosadora: são textos carregados de poesia. Difícil seria dizer qual é a mais bela das crônicas, qual a que mais encanta.

Antonio Candido (1992, p. 15) conta-nos que o gênero primeiramente apareceu como folhetim, firmando-se como crônica ao consolidar-se o jornal como veículo informativo cotidiano e de maior tiragem (meados do século XIX), “[...] e até se poderia dizer que sob vários aspectos é um gênero brasileiro, pela naturalidade com que se aclimatou aqui e a originalidade com que aqui se desenvolveu”. Para o estudioso, "[...] foi no decênio de 1930 que a crônica moderna se definiu e consolidou no Brasil, como gênero bem nosso" (Ibidem, p. 17), exercitado por inúmeros jornalistas e escritores. 
Cecília Meireles - a Bela e as Feras e a Bela e a Fera

\section{Explica Antonio Candido que}

A crônica não é um 'gênero maior'. Não se imagina uma literatura feita de grandes cronistas, que lhe dessem o brilho universal dos grandes romancistas, dramaturgos e poetas. Nem se pensaria em atribuir o Prêmio Nobel a um cronista, por melhor que fosse. Portanto, parece mesmo que a crônica é um gênero menor. (Ibidem, p. 13).

Todavia, é o próprio Candido (1992, p. 13-14) que, mais à frente, no mesmo artigo, diz que a crônica,

Na sua despretensão, humaniza; e esta humanização lhe permite, como compensação sorrateira, recuperar com a outra mão uma certa profundidade de significado e um certo acabamento de forma, que de repente podem fazer dela uma inesperada embora discreta candidata à perfeição.

O teórico ainda diz que a crônica “[...] pega o miúdo e mostra nele uma grandeza, uma beleza ou uma singularidade insuspeitadas”. (Ibidem, p. 14). E, “[...] quando passa do jornal ao livro, nós verificamos meio espantados que a sua durabilidade pode ser maior do que ela própria pensava.” (Ibidem, p. 14-15). Essa humanização de que fala Candido encontramos nas crônicas de Cecília Meireles, deixando escorrerem de suas franjas essas características todas apontadas pelo estudioso. Registradas nos livros, várias décadas após serem produzidas, as crônicas cecilianas permanecem atuais, ou melhor, atemporais, sempre ofertando, generosamente, a dádiva de beleza, delicadeza, sensibilidade e poesia - tão ao jeito da autora.

Como viajante, Cecília repousa seu olhar contemplativo em tudo que vê, daí colhendo farto material para suas crônicas. É ela mesma que diferencia o turista do viajante. O turista é feliz, munido de máquina fotográfica, guia turístico e vocabulário sucinto. "O viajante é criatura menos feliz, de movimentos mais vagarosos, todo enredado em afetos, querendo morar em cada coisa”. (MEIRELES, 2003, p. 256). Enquanto o turista já volta para casa, cercado de fotografias,

[...] o viajante apenas inclina a cabeça nas mãos, na sua janela, para entender dentro de si o que é o sonho e o que é realidade [... ] e o viajante imóvel é uma pessoa sem data e sem nome, na qual repercutem todos os nomes e datas que clamam por amor, compreensão, ressurreição. (Ibidem, p. 260). 
É essa mesma viajante, descrita por Cecília, que encontramos em suas crônicas; a viajante que intenta conhecer o interior das criaturas e das coisas, compreender sentimentos, que perscruta o passado de cada lugar, que escuta cada canto e se perde em labirintos de pensamentos, nuvens e poesia.

Na coleção de prosa da autora, o primeiro dos três tomos com as crônicas de viagem traz como texto primeiro "A Bela e as Feras”, objeto de análise neste trabalho. A intertextualidade com o conto “A Bela e a Fera” já se explicita no título. Publicada em 23 de outubro de 1941, no jornal A Manhã, a crônica foi escrita provavelmente em 1940, quando Cecília esteve no México.

Diz Bruno Bettelheim (2000) que a versão mais antiga do que se conhece hoje como o conto de fadas "A Bela e a Fera" é registrada por Perrault (Paris, 1628-1703), como "Riquet à la Houppe”, e em muito difere das atuais versões. Uma princesa boba acaba se apaixonando por um homem disforme, porém brilhante e de grande caráter. O amor produz a mágica transformação: a feiúra física passa a nada representar diante da beleza interior, enquanto a estupidez da princesa parece inteligência diante de seu olhar para o jovem. Perrault deixou claro que "[...] a moral da história é que a beleza, seja física ou mental, reside no enfoque de quem contempla.” (BETTELHEIM, 2000, p. 343). Para Bettelheim, o fato de Perrault ter explicitado a moral da história faz com que ela deixe a desejar como conto de fadas. (Ibidem, p. 343). Contudo, ao fazer adaptações literárias de histórias de tradição oral, Perrault teve mesmo o cuidado de finalizá-las com conceitos morais, associando ao aspecto lúdico um teor pedagógico.

Os Irmãos Grimm (Alemanha, 1785 - 1863 e 1786 - 1859) também escreveram uma versão de “A Bela e a Fera”. Compreendendo a importância de preservar as histórias tradicionais do povo alemão, contadas de geração a geração, os dois irmãos (Jacob e Wilhelm) recolheram histórias transmitidas por relatos orais dentre seu povo e muitas registradas por padres, desde a Idade Média.

Segundo Bettelheim, a mais conhecida versão de "A Bela e a Fera” provém de história editada em 1757, contada por Madame Leprince de Beaumont, que, por sua vez, baseia-se em versão francesa do mesmo tema, escrita

\footnotetext{
Literatura infantil: Charles Perrault (1628-1703). Disponível em: < www.graudez.com.br/litinf/autores/ perrault/perrault.htm>. Ac'esso em: 6/6/2009.

${ }^{2}$ Irmãos Grimm, elementos biográficos. Disponível em: < http://www.educ.fc.ul.pt/docentes/opombo/ cinema/dossier/cinderela/grimm_biografia.htm>. Acesso em: 6/6/2009. 
anteriormente por Madame de Villeneuve. (BETTELHEIM, 2000, p. 343). Em tal versão, o pai de Bela (que tem três irmãos e mais duas irmãs), precisando viajar a negócios, para tentar recuperar a fortuna perdida, no retorno, ainda pobre, se perde e se vê diante de um palácio; ali entra, se abriga e se alimenta e descansa, sem, contudo, encontrar qualquer pessoa. Pela manhã, ao sair do palácio, vê no jardim belas rosas e as colhe para levá-las a Bela. Nesse momento, surge a Fera, indignado por ter acolhido o homem, e este agora a lhe roubar as rosas; quer castigá-lo com a morte. O pai de Bela pede perdão e explica o motivo de seu ato. A Fera permite que o homem leve as flores para a filha, porém ele deve retornar para morrer, ou trazer-lhe a jovem para ocupar seu lugar. Pensando em rever os filhos antes de morrer, o homem vai para casa, levando as rosas e um cofre cheio de ouro dado pela Fera. Em casa, conta o que lhe aconteceu, e Bela, contra a vontade do pai, insiste em acompanhá-lo ao palácio. Ao saber que ela veio por livre vontade, a Fera manda para casa o pai e mantém a moça no palácio, onde, contudo, ela é muito bem tratada, tendo todos os desejos satisfeitos mesmo antes de expressá-los. Todas as noites, à hora do jantar, a Fera visita Bela. Passa a pedi-la em casamento, porém a jovem, com delicadeza, sempre recusa, o que deixa o homem muito triste. Numa noite, a Fera pede a Bela que então nunca o abandone; a jovem promete, mas solicita permissão para ver o pai, pois vira em um espelho que ele está muito mal. A Fera consente, no entanto lhe dá um prazo para retornar, ou ele morrerá. A jovem, por encanto, amanhece em casa. Os irmãos estão no exército e as irmãs, casadas, infelizes e invejosas, persuadem Bela a ficar mais uns dias. Bela aquiesce, mas uma noite sonha que a Fera a recrimina, aflita e agonizante. Bela deseja rever a Fera e, por magia, se vê no palácio. Encontra a Fera desolada e quase morta. Bela já percebera que muito se afeiçoara àquele homem e agora entende que o ama. Confessa-lhe seu amor e acede em casar-se com ele. A Fera então se transforma em um lindo príncipe. (BETTELHEIM, 2000, p. 343-345). O jovem conta a Bela que, há muito tempo, sendo um rico e respeitado príncipe, fora visitado por uma mendiga que lhe pedira comida e abrigo. Grosseiro e impiedoso, expulsara a mulher, para então descobrir que ela era sua fada madrinha, disfarçada, que o testava. Ela o condenou a viver com forma de monstro, até que seu coração se transformasse pelo sofrimento e amor, e que, mesmo com aquela aparência, por suas qualidades interiores fosse amado e aceito em casamento.

\footnotetext{
${ }^{3}$ Fantasia da vida: A Bela e a Fera (A Bela e o Monstro em Portugal). Disponível em: $<$ http://fantasiada-vida.blogspot.com/2008/03/bela-e-fera-bela-e-o-monstro-em.html >. Acesso em: 4/6/2009.
} 
O conto "A Bela e a Fera” tem sido contado e recontado, além de receber versões teatrais e cinematográficas. Na literatura, tem sido objeto de releituras, sendo reaproveitado, por exemplo, por Clarice Lispector, que escreveu o conto "A Bela e a Fera ou a ferida grande demais", no qual uma jovem senhora, rica e linda, ao ser abordada por um mendigo que tem uma grande ferida na perna, choca-se, porém para e questiona-se sobre a realidade do mundo e a sua própria; desabituada a pensar, esse foi o momento em que refletiu sobre sua condição de riqueza e futilidade, descobrindo-se mendiga de amor. (LISPECTOR, 1995). Anna Flora Martins (1996), em uma história infanto-juvenil, aborda a questão das diferenças com as quais as garotas precisam conviver e que podem se equilibrar ou provocar algum desequilíbrio, mas que fazem parte de seu crescimento e desenvolvimento. Paula Giannini (2003) faz uma adaptação teatral, unindo a contação da história antiga e um acontecimento similar em tempos atuais. Vemos, assim, como o conto permanece utilizado, explorado, readaptado.

\section{Crônica e conto: interlocução}

E roda a melancolia/ seu interminável fuso!

Cecília Meireles

A crônica ceciliana “A Bela e as Feras" relata a experiência da autora em uma tarde de domingo, no México, quando foi a uma tourada. Cecília (1998, p. 1) achara caros os ingressos, mas quem os vendeu afirmou "que seria uma coisa soberba" e que a toureira, uma peruana, tinha apenas 17 anos. Não veio o sol que a autora esperava e, sim, "[...] havia nuvens e nuvens que se alastravam lentamente, fazendo entardecer antes do tempo." (Ibid). Embora seja ela a "poeta das nuvens", quando elas fazem "entardecer antes do tempo", é como se esse comentário antecipasse o sentimento da autora diante do que presenciaria; é como se um sentimento de melancolia futura já se instaurasse. A cronista descreve o ambiente, antes do espetáculo. Sua visão da entrada da moça é assim relatada:

Ela era delgada, branca e loura. Tinha dezessete anos. Estava toda de preto. Montava admiravelmente. Quando levantou a cabeça para agradecer os aplausos, sob as abas retas do chapéu, de tira passada pelo queixo, brilharam seus grandes olhos claros, exatamente como duas águas-marinhas. 
Cecília Meireles - a Bela e as Feras e a Bela e a Fera

Deu uma volta pela arena, exibindo por todos os lados sua esbelta e sóbria elegância. De costas, via-se-lhe a trança de ouro suave enrolada sobre a nuca. [...]

Sendo tão delgada e branca e loura, ela me fazia pensar num modelo de santa gótica. Mas era toureira. Toureira. (MEIRELES, 1998, p. 2).

Em seguida, assim é o touro apresentado:

O touro negro entrou distraído e pacífico. Não olhou para o público nem para a gente da praça. Tanto que as roupas de lantejoulas dos peões ficaram numa sombra lamentável, sem nenhuma expressão.

O touro vinha meio adormecido no seu corpanzil lustroso, e seus olhos não tinham previsões de nada. (Ibid).

Nos dois excertos em que a cronista apresenta respectivamente a toureira e o touro, podemos perceber os contrastes entre as duas figuras e em cada uma delas. Ela, branca e delgada; ele, negro e imenso. A toureira exibe-se para o público; tão jovem, linda e com delicadas características, lembra uma santa gótica, porém é uma toureira (e a expressão se repete, como a reforçar o peso que tem). O touro, de corpanzil brilhoso, entra sem dar importância ao público ou ao momento, e sua indiferença é tanta que tira o brilho e a graça das vestimentas dos peões.

\section{O espetáculo se inicia:}

A toureira começou sua dança de tentação. Esvoaçava diante do touro, tornando alado o cavalo. Com seus ares de anjo, tocava-o com a lança, feria-lhe o negro corpo lustroso, e a cada instante eu pensava que ela tratava de o desencantar. Pensava que ela era Circe, pensava coisas sobrenaturais, pensava que aquele grande corpo ia cair num dado momento como um pesado vestido, um disfarce, um esconderijo, uma praga - e de dentro da Fera surgiria um moço delgado e louro que ajudaria a descer do cavalo a jovem amazona e a conduziria, pela praça, de braço dado, ao som da música, sob uma chuva de flores...

Mas via apenas a grossa pasta de sangue brotando das feridas abertas. Ai! como braçadas de cravos vermelhos sobre cetim negro. E a Bela dançando a sua fina dança de anjo e de naja. Os peões sumiam-se. A arquibancada apagava-se. Embaixo e dos lados tudo era como em cima: cinza de nuvens. Só existiam a Bela e a Fera. (MEIRELES, 1998, p. 2-3). 
No trecho acima, a moça - a Bela - é anjo e tentação, anjo e naja. Ao mesmo tempo em que é graciosa em sua dança angelical, é traiçoeira; enquanto parece tocá-lo para desencantá-lo - feiticeira: fada e bruxa; Circe -, na verdade fere o touro. Encontramos elementos míticos e místicos: cavalo alado e Circe (presentes nas tragédias gregas), encantamento, desencantamento e praga, a Bela e a Fera e outros elementos de contos de fadas; anjo e víbora, coisas sobrenaturais. As flores almejadas brotam das feridas no corpo do touro, em sangue, "[...] como braçadas de cravos vermelhos sobre cetim negro" (Ibidem, p. 3) - belíssima imagem poética, mostrando o contraste cromático a refletir o semântico. E as nuvens plúmbeas se refletem no ambiente, onde tudo é cinza de tristeza, ou como uma tentativa de relativizar todos os opostos apresentados. Contudo, os contrastes saltam novamente aos olhos, pois “[...] só existiam a Bela e a Fera” - referência explícita ao conto homônimo.

Ao ver o touro resfolegando, a cronista, enternecida, pensa: “'Por que não te desencantas depressa?' [...] 'Ainda que morresses, valia a pena desencantares-te! Não serás mais a Fera. [...] Nunca mais te ferirão assim, para te despertarem'” (Ibid) - como se o touro (a Fera) pudesse transformarse em príncipe e se salvar.

Contemplando o touro cravado de bandarilhas, seu corpo - “[...] uma ilha negra, toda sulcada por vagarosos rios vermelhos" (Ibid) -, observa que "A toureira sorria vitoriosa. Como seria o seu rosto se o milagre se desse, e a Fera se transformasse num homem ou num santo?” (Ibid). Enquanto espera a impossível e onírica metamorfose, novamente a cronista integra o mítico e o místico. E aqui já não é a moça a parecer uma santa, porém o touro, humanizado e santificado - reflexo de que é para o animal que aponta o pêndulo afetivo da cronista.

Na continuação da batalha na arena, a autora intensifica os contrastes entre as criaturas e dentro delas, a dubiedade das palavras escolhidas, desenvolvendo ainda a sutil transformação que nas personagens se opera aos olhos vigilantes e sensíveis da assistente:

A Bela era delgada, branca e loura. Ficava mais loura e mais branca e mais delgada perto da grande Fera negra. Ficava mais pura junto às fontes de sangue que lhe abrira no corpo fatigado. Mais fria diante da fumaça que estertorava em suas narinas. (MEIRELES, 1998, p. 3). 
A segunda oração repete o sentido da primeira, aplicando-lhe mais veemência; todavia o prolonga, o distende, e reverbera, ao utilizar os elementos na ordem inversa. Assim, ao colocar essa segunda oração sucedida pela "grande Fera negra”, intensifica o contraste entre as figuras da toureira e do touro - seja na aparência, nas imagens visuais ou nas semânticas - nesse ponto e no que segue até o final do período. A pureza da toureira, advinda de sua brancura e lourice, contrasta com o rubro de sangue (intensificado ao brotar do corpanzil negro, como se de fontes brotasse) e com a capacidade que a jovem demonstra em ferir o touro - um corpo fatigado, portanto, fragilizado, apesar do tamanho (e aqui se apresenta mais um contraste).

$\mathrm{Na}$ arena, o bailado de morte continua, até que a jovem, com certeiro golpe, crava no touro uma lança. Então,

A Fera caiu como de joelhos. Dos rios de sangue do seu corpo iam rolando cravos encarnados cada vez maiores. A arena encheu-se de um acre perfume de jardim fantástico.

A toureira cumprimentava para um lado e para o outro. Tinha dezessete anos. Delgada, branca e loura. Saíam chispas de estrelas dos seus olhos azuis. (Ibidem, p. 4).

As imagens visuais - poéticas, cromáticas, contrastantes e carregadas de sentidos -, tão presentes no texto, agora se fazem acompanhar de imagens olfativas, com o perfume acre desprendido pelo sangue, como advindo de um fantástico jardim. Em seguida, são acrescidas imagens táteis, térmicas e cinestésicas, proporcionando sinestesia, quando a Fera "[...] ia sendo arrastada para fora da arena, coberta das flores que enroxeciam sobre a sua imóvel negrura, ainda palpitantes e quentes.” (Ibid).

Veio "O segundo touro, esse era cor de bronze. Esse entrou pela arena adentro bufando fogo, à procura da Bela. E a Bela saltou na sua frente, do mesmo modo, como um anjo de tentação.” (Ibidem, p. 5). Forte e de olhos sanguinários, mesmo reiteradamente ferido pela toureira, o touro de bronze arremete contra a jovem, partindo-lhe a espada. "Foi quando a Bela empalideceu. Tornou-se um marfim seu rosto" (Ibid), e a multidão, em expectativa onírica, já a via morrer, "[...] pálida, os cabelos de ouro jorrando, desmanchados...” (Ibid), na descrição imagética da cronista. Porém, com nova lança em mão, “[...] a morte desprendeu-se do seu peito e abraçou a Fera, que caiu lânguida, para descansar da luta contra a Bela, envolta no veludo de sangue que ia descendo do seu corpo de bronze.” (Ibid). 
Nesse segundo combate, vemos a aparente desigualdade da luta, com duas figuras opostas em tamanho e força - um touro de bronze, grande, violento e sanguinário (feroz, a Fera), contra a jovem angelical, delgada, pálida e até amedrontada (delicada, a Bela). Contudo, é esse touro de bronze (que, sendo touro e de bronze, toma conta de nossa mente com a exacerbação de sua forma e força), feroz e sanguinário, que cai, derrotado pela mocinha delicada que 0 golpeia com o fio da morte.

Em momento de evocação, a cronista conta:

Lembro-me do rosto branco e azul da toureira. Da sua trança de ouro. Do seu sorriso. Tinha os dentes unidos, numa fila perfeita, e os lábios de fita fina.

Lembro-me do touro negro e do touro de bronze, deitados de bruços, levados para fora da praça, vencidos, arrastados numa prancha... Lembro-me daquele cheiro de sangue, pastoso e forte. (Ibid).

Nesse excerto, novamente, a descrição da jovem: traços arianos e delicados, aparência perfeita, a típica figura idealizada dos contos de fadas; mas era uma toureira. Os dois touros, que em nosso imaginário já correspondem a figuras imensas, violentas, perigosas, aparecem agora de bruços numa prancha, vencidos, tendo seus corpos mortos carregados, enquanto exalam seu cheiro de sangue. E tais imagens, implicitamente, desfilam prenhes dos antagonismos que delas brotam. A carga imagética desse trecho - e presente por toda a crônica - se multiplica em sentidos que não se fizeram explícitos, contudo ali estão, a apontar a violência exercida contra esses animais e a crueldade contida no ser humano - mesmo sob capa angelical de beleza e fragilidade - e que por todos é aclamada. Cada vez mais nítido se torna o sentimento de empatia que a cronista nutre pelas feras, os touros.

Vemos, em toda a crônica, várias referências aos contos de fadas e outras especificamente de "A Bela e a Fera”: nas figuras da toureira e de cada um dos touros, a referência explícita à Bela e à Fera; a imagem de beleza idealizada da figura feminina, condizente com os contos de fadas; a esperança ou expectativa onírica de que o touro se desencante e se transforme em príncipe; elementos míticos, como encantamento, desencantamento e personagens vindos da mitologia grega. Tudo isso traz à mente o universo mágico que habita nosso imaginário desde a infância. 
Cecília Meireles - a Bela e as Feras e a Bela e a Fera

No final da crônica, a autora conta:

Murmurava comigo: ‘A Bela e as Feras... a Bela e as Feras...’ Em seguida, as Feras desapareciam. Em seguida, desaparecia a Bela... Depois, tudo se misturava. A Bela sorria com o corpo morto das Feras... As Feras choravam no corpo vivo da Bela... (MEIRELES, 1998, p. 6).

Nessas palavras finais, Cecília resgata mais uma vez o universo mágico dos contos de fadas, com o desaparecimento, como que por encanto, ora das Feras, ora da Bela; e depois com a mistura, e cada uma das criaturas aparecendo no corpo da outra. Tal universo mágico vem, contudo, carregado de melancolia; traz em seu bojo a reverberação dessa dualidade contida em cada criatura: as Feras, animais, aí são as vítimas, frágeis e indefesas, ainda que travestidas de grandes, fortes e ameaçadoras; a jovem, humana, figura feminina idealizada, bela e delicada aos olhos, dentro de si carrega a ferocidade que se esperaria dos touros.

Em A psicanálise dos contos de fadas, como indica o título da obra, Bruno Bettelheim imprime aos contos de fada uma análise sob os olhos da psicanálise, apontando a presença de conflitos edipianos na maioria das estórias de tais contos. Em vários desses, lembra ele, há o fato de que “[...] o intrépido herói mata dragões, luta com gigantes e monstros, bruxas e feiticeiros.” (BETTELHEIM, 2000, p. 320). Explicando o desejo do menino de afastar o pai e aproximar a mãe - questão não contemplada na análise aqui apresentada -, diz o autor que "O matador do dragão tem sempre que ser jovem, como a criança, e inocente.” (Ibidem, p. 142). Tais fantasias fariam parte do imaginário dos meninos, que se identificariam com o papel principal; sendo crianças e inocentes, não se sentiriam culpados por tais fantasias, porém como um orgulhoso herói - que depois salvará a princesa. (Ibidem, p. 141-142).

Afirma ainda Bettelheim que "As fantasias edípicas de glória são personificadas nos contos onde os heróis matam dragões e salvam donzelas." (Ibidem, p. 320).

Não é objetivo deste trabalho apresentar análises de caráter psicanalítico ou de conflitos edipianos. Contudo, parece apropriado o aproveitamento de tais comentários de Bettelheim. Bem, no caso dessa crônica, tais análises psicanalíticas se justificam e também se colocam às avessas. A jovem toureira corresponde à figura de juventude e inocência, quase como uma criança; linda e delicada, lembra uma santa gótica; principalmente sob o incentivo, o olhar 
admirado e os aplausos do público, certamente se sente uma heroína orgulhosa. No entanto, subverte a figura do rapaz corajoso que depois salvará a princesa; ela é a figura feminina - a que deveria ser salva por um príncipe, mas não o é -, contudo, é ela mesma que cumpre o papel de herói, que luta com figuras gigantescas e monstruosas, que ataca e mata o dragão.

\section{Conclusão}

mas sou de ontem e de agora,/ dentro dos despedaçados/ instantes de nenhuma hora...

Cecília Meireles

Toda essa crônica, além do universo mítico e mágico resgatado pela autora, é revestida pela acuidade visual característica de Cecília Meireles, que transita entre extremos semânticos e sensoriais, antagonismos: aparência/ essência, belo/feio, real/imaginário. A predominância de impressões visuais se revela nas belas descrições físicas e de vestuários, nos contrastes cromáticos e de formas, na delicadeza e significado das imagens poéticas, na expectativa da onírica metamorfose. Em Cecília, a visão vertical atenta, contemplativa e delicada, alia-se à linguagem poética, bordada em palavras de seda e arminho; sendo de ontem e de agora, seu olhar abarca todos os tempos, em "instantes de nenhuma hora [...]” (MEIRELES, 2001, p.680) -; tudo isso contribuindo com a beleza e a riqueza de significados. Gênero que seria fadado à efemeridade do cotidiano e do veículo em que circula, a crônica ceciliana se reveste de atemporalidade e alto grau de literariedade, além de mostrar que Cecília Meireles é inesgotável, seja como poeta ou como prosadora. De sua prosa, assim como de sua poesia, brotam "músicas límpidas,/ trançando sons de ouro e de seda." ${ }^{5}$ (Ibidem, p. 248).

\section{Referências}

AZEVEDO FILHO, Leodegário A. de. Apresentação. In: MEIRELES, Cecília. Crônicas de viagem, 1. Rio de Janeiro: Nova fronteira, 1998. p. XI-XV. (Cecília Meireles: obra em prosa).

\footnotetext{
4 Do poema “Pastora descrida”, de Cecília Meireles, incluído em seu livro Retrato natural, de 1949.

${ }^{5}$ Do poema “Inverno”, incluído em seu livro Viagem, de 1939. 
BETTELHEIM, Bruno. A psicanálise dos contos de fadas. Tradução: Arlene Caetano. 14. ed. Rio de Janeiro: Paz e Terra, 2000.

CANDIDO, Antonio. A vida ao rés-do-chão. In: CANDIDO, Antonio et al. A crônica: o gênero, sua fixação e suas transformações no Brasil. Campinas: Editora da UNICAMP; Rio de Janeiro: Fundação Casa de Rui Barbosa, 1992. p. 13-22.

Fantasia da vida: A Bela e a Fera (A Bela e o Monstro em Portugal). Disponível em: < http://fantasia-da-vida.blogspot.com/2008/03/bela-e-fera-bela-e-o-monstro-em.html >. Acesso em: 4/6/2009.

GIANNINI, Paula. A bela e a fera. Edição independente. Curitiba, 2003.

Irmãos Grimm, elementos biográficos. Disponível em: < http://www.educ.fc.ul.pt/docentes/ opombo/cinema/dossier/cinderela/grimm_biografia.htm >. Acesso em: 6/6/ 2009.

LISPECTOR, Clarice. A bela e a fera ou a ferida grande demais. In: . A Bela e a Fera. Apresentação: Vera Figueiredo. 5. ed. Rio de Janeiro: Francisco Alves, 1995. p. 105-118.

Literatura infantil: Charles Perrault (1628-1703). Disponível em: < www.graudez.com.br/ litinf/autores/perrault/perrault.htm>. Acesso em: 6/6/2009.

MARTINS, Anna Flora Ferraz de Camargo. A bela ou a fera. Ilustrações: Cláudio Martins. 4. ed. São Paulo: FTD, 1996. (Coleção Desafio de Crescer).

MEIRELES, Cecília. A bela e as feras. In: Crônicas de viagem, 1. Rio de Janeiro: Nova fronteira, 1998. p. 1- 6. (Cecília Meireles: obra em prosa).

MEIRELES, Cecília. “Inverno”. In: Poesia completa: Cecília Meireles. Rio de Janeiro: Nova Fronteira, 2001, p. $248-249$.

MEIRELES, Cecília. "Pastora descrida”. In: Rio de Janeiro: Nova Fronteira, 2001. v. 1, p. 679 - 680.

MEIRELES, Cecília. Roma, turistas e viajantes. In: Poesia completa: Cecília Meireles. Meireles. Seleção e prefácio: Leodegário A. de Azevedo Filho. São Paulo: Global, 2003. p. 256-260. (Melhores Crônicas).

Recebido para publicação em 06 maio 2010 Aceito para publicação em 10 maio 2010 